\title{
Ecologic Determinants of West Nile Virus Seroprevalence among Equids, Brazil
}

\author{
Edmilson F. de Oliveira-Filho, ${ }^{1}$ Carlo Fischer, ${ }^{1}$ Beatrice Sarah Berneck, \\ lanei O. Carneiro, Arne Kühne, Angelica C. de Almeida Campos, Jorge R.L. Ribas, \\ Eduardo Martins Netto, Carlos Roberto Franke, Sebastian Ulbert, Jan Felix Drexler
}

Among 713 equids sampled in northeastern Brazil during 2013-2018, West Nile virus seroprevalence was $4.5 \%(95 \% \mathrm{Cl} 3.1 \%-6.3 \%)$. Mathematical modeling substantiated higher seroprevalence adjacent to an avian migratory route and in areas characterized by forest loss, implying increased risk for zoonotic infections in disturbed areas.

W est Nile virus (WNV) is a widely distributed arthropodborne flavivirus transmitted predominantly by Culex mosquitoes (1). Among infected persons, $\approx 20 \%$ show clinical signs, such as mild fever, rash, joint pain, headache, vomiting, and diarrhea $(1,2) ; \approx 0.7 \%$ have severe illness, such as encephalitis, meningitis, acute flaccid paralysis, respiratory failure, and even death (1). Beyond vectorborne transmission, transfusion-transmitted WNV infections have endangered blood safety (3). Equids are susceptible to WNV and develop severe disease (fatality rate $\leq 30 \%$ ), are exposed to WNV vectors outside and in stables, and are spatially distributed near human settlements. Thus, equids can be sentinels for early detection of regional WNV activity (4).

In the Americas, WNV gained attention after its rapid spread in the United States beginning in 1999 (4). In South America, WNV dispersion is poorly understood. Seropositive horses were found in Colom-

Author affiliations: Charité-Universitätsmedizin Berlin, Berlin, Germany (E.F. de Oliveira-Filho, C. Fischer, A. Kühne,

A.C. de Almeida Campos, J.F. Drexler); Fraunhofer Institute for Cell Therapy and Immunology, Leipzig, Germany (B.S. Berneck, S. Ulbert); Federal University of Bahia, Salvador, Brazil (I.O. Carneiro, E.M. Netto, C.R. Franke); Bahia State Agricultural Defense Agency, Salvador (J.R.L. Ribas); Sechenov University, Moscow, Russia (J.F. Drexler); German Centre for Infection Research, Berlin (J.F. Drexler)

DOI: https://doi.org/10.3201/eid2709.204706 bia in 2004 (5) and in Argentina in 2006 (6). In Brazil, the largest country in South America, serologic studies from central, southeastern, and northeastern regions suggested WNV circulation among horses since at least $2009(7,8)$. Human WNV infection was described only once, in 2014, from a patient in northeastern Brazil with encephalitis (9). In 2018, a WNV strain was isolated and sequenced during an epizootic in horses in the southeastern coast (10). The horse-derived virus from Brazil clustered with strains detected in different birds in the United States in 2002 and 2005 (10), indicating that migratory birds could play a role in WNV transmission in Brazil.

Serologic WNV data from equids along avian migratory routes are scarce. In the only available study from northeastern Brazil, 1/88 horses was WNV seropositive with a low neutralization titer (7). In the absence of testing for cocirculating flaviviruses, a low WNV antibody titer could be caused by infections with other flaviviruses, eliciting cross-reactive antibodies (11). We conducted a seroepidemiologic study among equids to investigate the spread of $\mathrm{WNV}$ in northeastern Brazil.

\section{The Study}

We collected serum samples from 713 equids, including horses and mules, sampled as part of routine veterinary surveillance activities during 2013-2018 in the state of Bahia in northeastern Brazil. The animal ethics committee of the Federal University of Bahia approved the sampling and analyses (authorization no. 55/2017). Sampling covered a large area that connects the location of the human case from 2014 and the 2018 horse epizootic $(9,10)$. The area is adjacent to the Atlantic, northeastern, and central avian migratory routes (Figure 1).

These first authors contributed equally to this article. 


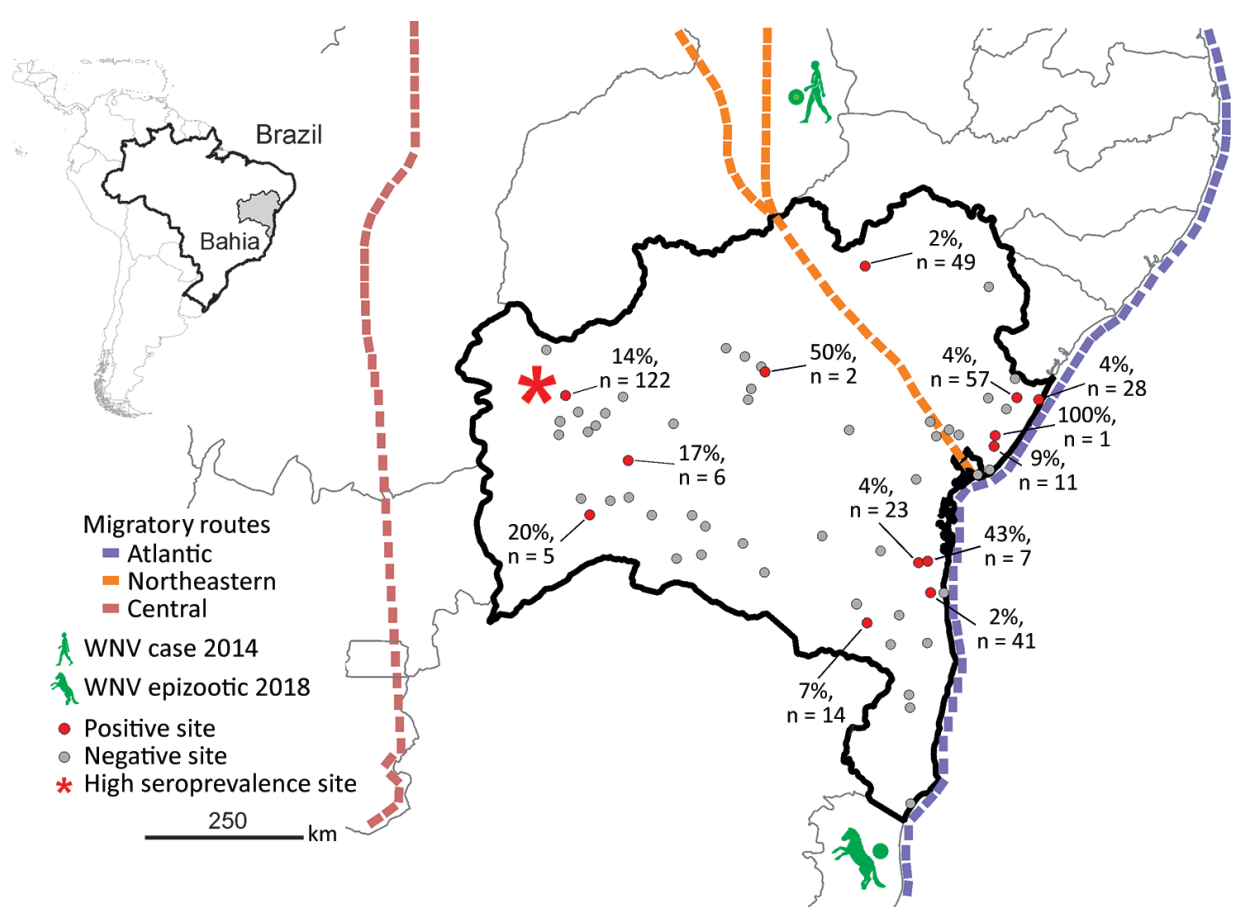

Figure 1. Geographic distribution and $\mathrm{PRNT}_{90}$-validated West Nile virus seroprevalence among equids per sampling site in Bahia State, Brazil. Inset shows location of Bahia State in northeastern Brazil. Sample sizes are shown only for locations with seropositive animals. Avian migratory routes are based on the 2016 annual report of the Chico Mendes Institute for Biodiversity and Conservation (https://www.researchgate. net/publication/292980285 Annual_Report_of_Flyways_ and_Priority_Areas_for Migratory_Birds_in_Brazil_ Relatorio_anual_de_rotas_e areas_de_concentracao_de_ aves_migratorias_no_Brasil). $\mathrm{PRNT}_{90}, 90 \%$ plaque-reduction neutralization tests.

Figure 2. WNV seroprevalence among equids, Brazil. A) ELISA absorbance values displayed as sample to cutoff ratio, as previously described (2). We increased the ELISA cutoff by $10 \%$ above which samples were considered positive to maximize specificity because the ELISA was not originally validated for horses in Latin America, which are infected by more Japanese encephalitis serocomplex viruses compared with horses in Europe. Dotted orange line represents the 1.1 positivity cutoff. B) Reciprocal $\mathrm{PRNT}_{90}$ titers for WNV and other flaviviruses. Statistical significance levels were inferred by using the Kruskal-Wallis test. Bars indicate mean. Graph created by using Prism (GraphPad software, https:// www.graphpad.com). C) Distinction of heterotypic serum samples based on the endpoint titers of various flaviviruses.
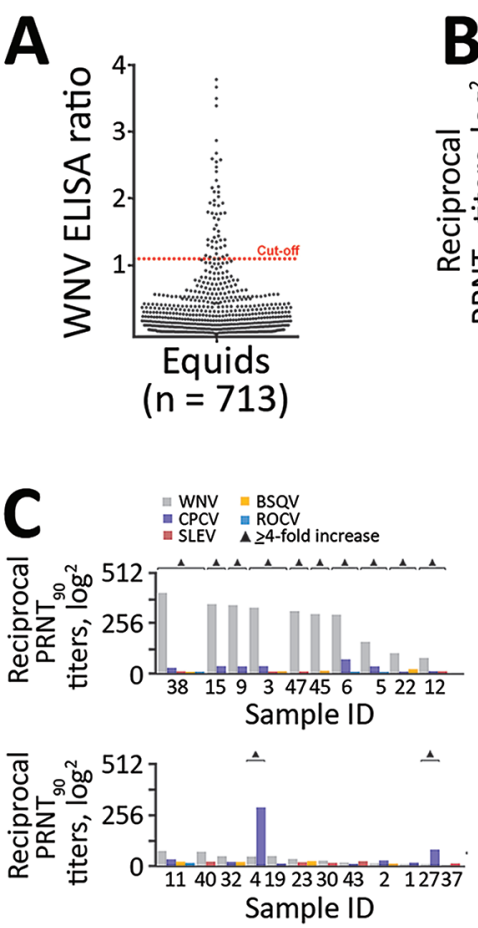
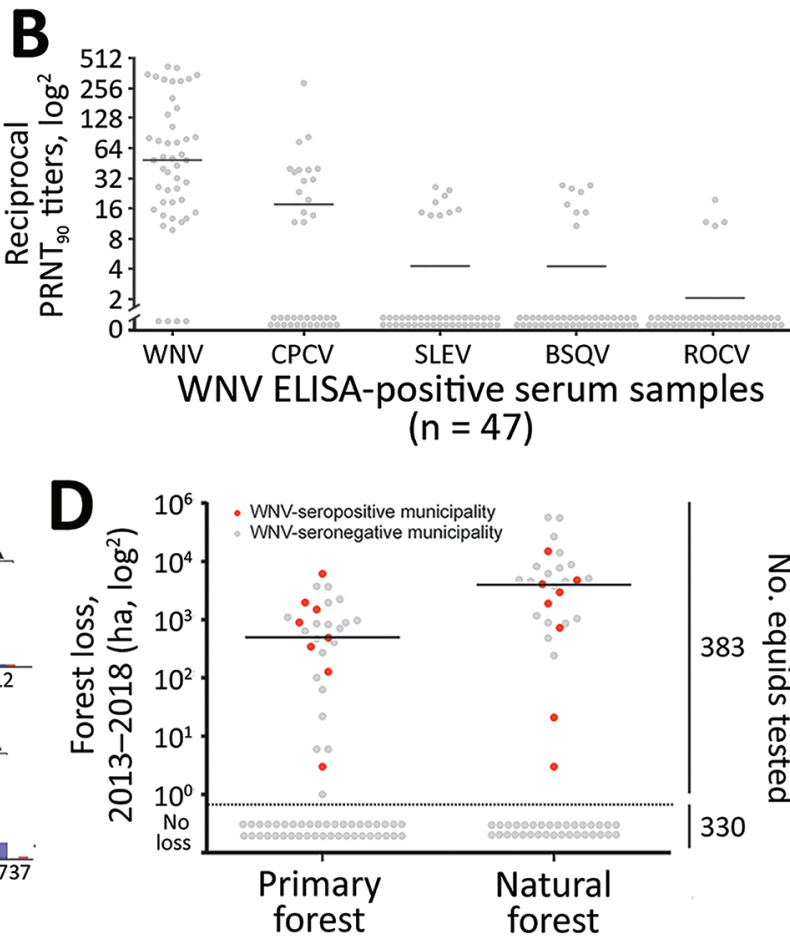

Triangles indicated endpoint

titers $\geq 4$-fold. D) Effects of forests and forest loss on WNV seropositivity and seronegativity among equids in municipalities, Brazil. Natural forest is made up of introduced or native tree or vegetation that have reproduced naturally, without help or (human) intervention. Primary forest is made up of intact and nonintact natural forest and refers to areas that reached the final stage of succession during 2013-2018. Data on primary and natural forest were retrieved from Global Forest Watch (http://www. globalforestwatch.org). Right y-axis represents number of total number of equids tested for seroprevalence. Horizontal bars indicate means. Areas below dotted line had no forest loss. BSQV, Bussuquara virus; CPCV, Cacipacoré virus; ha, hectare (10,000 m2); PRNT90, 90\% plaque-reduction neutralization test; ROCV, Rocio virus; SLEV, Saint Louis encephalitis virus; WNV, West Nile virus. 
For antibody screening, we used an experimental WNV IgG ELISA based on a fusion loop envelope antigen containing mutations. We chose this ELISA to decrease the chances of cross-reactivity with antibodies elicited by other flaviviruses (2). Among 713 serum samples, $47(6.6 \%, 95 \%$ CI $4.9 \%-8.7 \%)$ yielded positive ELISA results (Figure 2, panel A). Beyond WNV, horses in Latin America frequently are infected with Saint Louis encephalitis virus (SLEV), Cacipacoré virus (CPCV), Rocio virus (ROCV), and Bussuquara virus (BSQV) (12); and WNV, CPCV, and SLEV all belong to the Japanese encephalitis serocomplex (Appendix Figure 1, https:/ / wwwnc.cdc.gov/EID/article/27/9/204706-App1.pdf). Serologic analyses for WNV-specific antibodies in horses could be compromised by crossreactive antibodies against other flaviviruses, eliciting potentially false-positive test results (11). Therefore, we confirmed ELISA-based WNV antibody detection by comparing the endpoint titers for the $90 \%$ plaque-

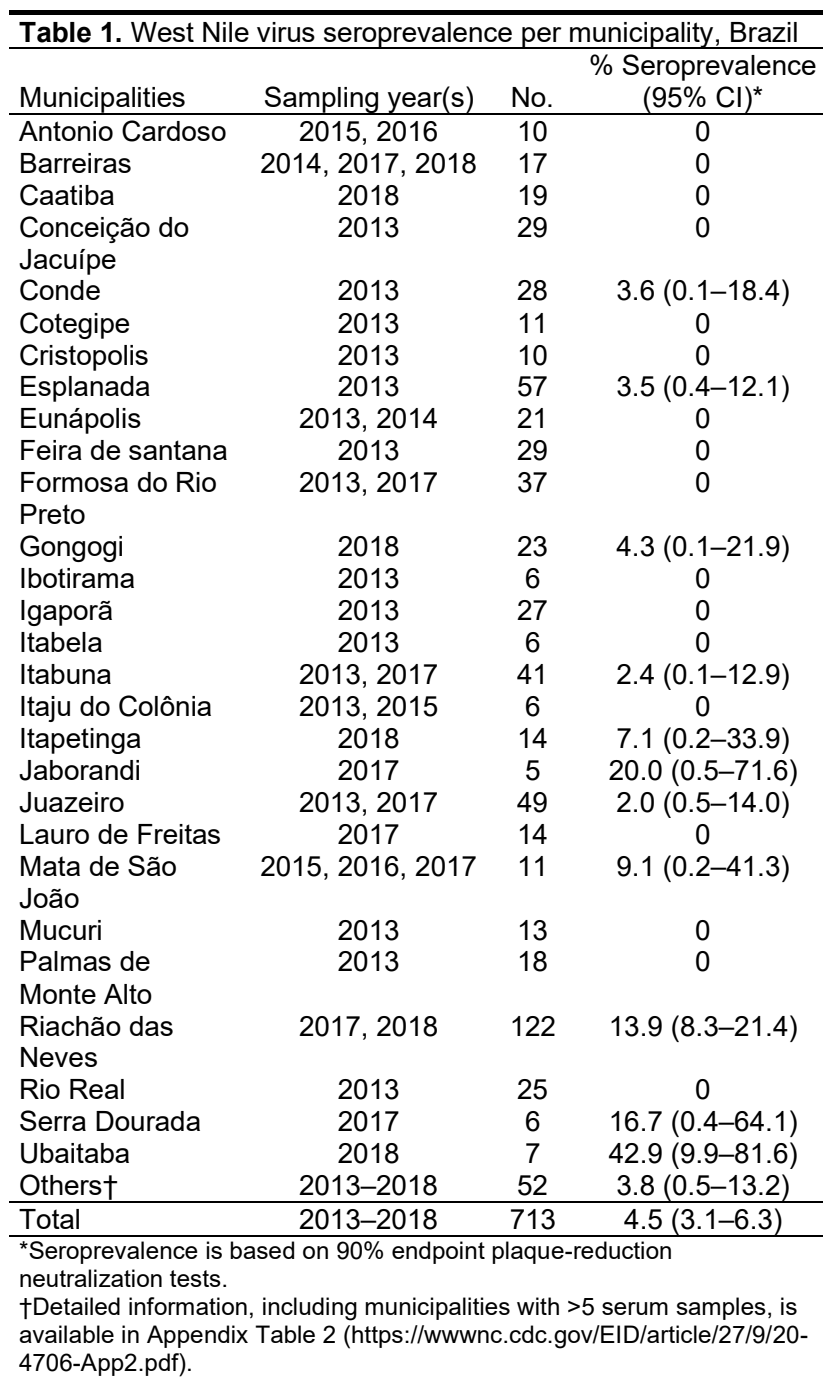

reduction neutralization tests $\left(\mathrm{PRNT}_{90}\right)$, considered the standard for arbovirus serologic testing, for WNV, $\mathrm{CPCV}, \mathrm{SLEV}, \mathrm{BSQV}$, and ROCV in all 47 ELISA-positive serum samples. Of the 47 samples, $20(44.7 \%)$ neutralized WNV only in PRNT ${ }_{90}$; another $22(46.8 \%)$ showed heterotypic reactions for WNV, CPCV, or SLEV (Figure 2, panel B). Averaged endpoint titers were significantly higher for WNV than for the other flaviviruses $(p<0.0001)$ and exceeded those for CPCV, SLEV, BSQV, or ROCV by $\geq 4$-fold in 12/22 heterotypic samples (Figure 2, panel C), a titer difference commonly considered decisive in flavivirus serology. Thus, $68.1 \%$ (32/47) of ELISA-positive samples had WNV-specific antibody responses (Figure 2, panel C); 4 samples were seronegative for all 5 flaviviruses by $\mathrm{PRNT}_{90}$, potentially because of differential sensitivity of ELISA and PRNT. No samples had higher SLEV, BSQV-, or ROCV-specific $\mathrm{PRNT}_{90}$ titers compared with WNV, but 2 ELISA-positive samples had $\geq 4$-fold endpoint titers for CPCV compared with WNV and other flaviviruses (Appendix Table 1). These findings substantiated WNV and CPCV cocirculation among equids in northeastern Brazil, which is consistent with previous data on CPCV circulation in another region of Brazil (12), and high specificity of the ELISA-based screening algorithm.

PRNT $_{90}$ validated the overall WNV seroprevalence of $4.5 \%$ (32/713 samples; 95\% CI 3.1\%-6.3\%), which we used for downstream analyses (Table 1). We noted seropositive animals in 11/28 municipalities distributed over $\approx 900 \mathrm{~km}^{2}$, suggesting wide geographic spread of WNV (Table 1; Figure 1). We observed a concentration of positive samples in 2018 (Appendix Figure 2), and in 1 municipality (Figure 1), comprising 9 different seropositive farms with an average seroprevalence of $13.9 \%$ (95\% CI 8.3\%-21.4\%). Antibody levels typically decline over time after flavivirus infection (13), which might bias positivity rates of serologic tests. However, WNV-specific $\mathrm{PRNT}_{90}$ endpoint titers were significantly lower in 2018 than in the preceding years by Mann-Whitney test $(\mathrm{p}=$ 0.002 ), excluding a bias from hypothetically more recent WNV infection in the animals sampled in 2018 (Appendix Figure 3).

We performed generalized linear model analyses and principal component analysis to compare 12 environmental, ecologic, and demographic factors potentially affecting WNV seroprevalence (Table 2; Appendix Figure 4). Anthropogenic changes of pristine habitats can increase the abundance of zoonotic pathogens (14), potentially including arboviruses like WNV (15). Indeed, the model considering forest loss, but not the model considering tree cover alone, was 
Table 2. Mathematical modeling of ecologic factors potentially affecting West Nile virus seroprevalence, Brazil ${ }^{\star}$

\begin{tabular}{|c|c|c|c|c|c|c|c|c|}
\hline Model & $\mathrm{AIC}$ & $\triangle \mathrm{AIC}$ & AW & $p$ value & OR $(95 \% \mathrm{Cl})$ & $\begin{array}{c}\text { Maximum OR difference } \\
\text { among study sites } \ddagger\end{array}$ & $\rho \S$ & Comment\# \\
\hline \multicolumn{9}{|l|}{ Distance to bird route, $\mathrm{km}$} \\
\hline Coastal & 248.02 & 0.00 & 0.56 & 0.001 & $1.002(1.001-1.004)$ & 4.527 & 0.09 & + \\
\hline Northeastern & 1.41 & 3.3 & 0.10 & & & & 0.08 & + \\
\hline Central & 52.17 & 4.16 & 0.07 & 0.014 & $0.999(0.997-1.000)$ & & -0.08 & - \\
\hline Forest loss, $y / n$ & 250.38 & 2.37 & 0.17 & 0.005 & $5.106(1.518-31.796)$ & 5.106 & 0.09 & + \\
\hline $\begin{array}{l}\text { Presence of natural or } \\
\text { primary forest, } y / n\end{array}$ & 253.39 & 5.38 & 0.04 & 0.029 & $3.186(1.111-13.48)$ & & 0.08 & + \\
\hline Altitude, m & 255.53 & 7.51 & 0.01 & 0.105 & $1.002(1.000-1.004)$ & 3.518 & 0.06 & + \\
\hline Mean temperature, ${ }^{\circ} \mathrm{C}$ & 8.03 & 10.01 & & & & & -0.04 & - \\
\hline Hottest qu & & 7.55 & 1 & & & & -0.04 & - \\
\hline Human dens & & 7.74 & & & & & & + \\
\hline Tree cove & 37 & 8.8 & & & & & & _- \\
\hline no./km2 & 8.10 & 10. & & & & & & - \\
\hline Mean precipitation, $\mathrm{mm}$ & 258.15 & 10.14 & 0.00 & 0.948 & $1.000(0.999-1.001)$ & 1.047 & -0.01 & - \\
\hline \multicolumn{9}{|c|}{ 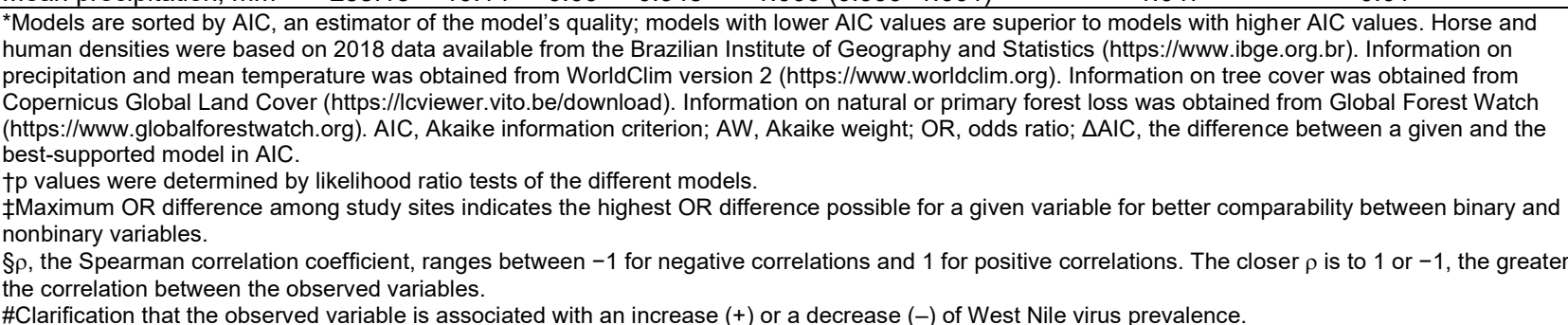 } \\
\hline
\end{tabular}

significantly associated with higher WNV seroprevalence (odds ratio [OR] 5.106, 95\% CI 1.318-31.796; $p=$ 0.005) (Table 2). Model results were consistent with a higher proportion of WNV-seropositive sites in disturbed areas compared with pristine areas by $\chi^{2}$ test $(p=0.009)$ (Figure 2, panel D). Higher WNV seroprevalence in disturbed areas was not biased by the number of animals living in those sites compared to sites from pristine areas. By Student $t$-test, neither the overall number of animals nor the number of animals per site differed significantly between disturbed $(p=$ 0.9 ) and pristine areas $(p=0.2894)$ (Figure 2, panel $D$; Appendix Figure 5).

Because the geographic distribution of both the 2018 horse epizootic and the only known human case might be linked geographically to the northeastern and coastal avian migratory routes (Figure 1 ), we included distances to avian routes in model analyses of WNV seroprevalence. Proximity to the central avian migratory route was associated with higher WNV seroprevalence (Table 2; Appendix Figure 4). This finding was consistent with other seroprevalence studies, indicating the presence of WNV in horses in the central region in Brazil $(7,8)$, but failed to connect the WNV detections in Brazil to geographically adjacent avian migratory routes. Our data were consistent with prior studies of WNV ecology, but the explicatory power of our models was low despite statistical significance (Table 2; Appendix Figure 4).
Our study was limited by absence of longitudinal samples from individual sampling sites, lack of information on animal trade and animal age, and relatively low numbers of seropositive animals from individual sites. Thus, we cannot exclude biases affecting the accuracy of our modeling approach. However, our large sample and the combination of thorough serologic analyses and mathematical modeling enabled robust estimates of WNV spread that can guide prospective studies.

\section{Conclusions}

Our findings of substantial WNV seroprevalence in equids in Brazil warrants WNV surveillance in cases of acute neurologic disease in humans and horses. In addition, blood products should be screened in areas of Latin America with high risk for WNV.

\section{Acknowledgments}

We thank Sandra Junglen and Anne Kopp for providing the Saint Louis encephalitis virus strain; Xavier de Lamballerie for providing the Cacipacoré virus, Bussuquara virus, and Rocio virus strains; and Patricia Tscheak for technical assistance. We thank the Friedrich-Loeffler-Institut, Bundesforschungsinstitut für Tiergesundheit, Insel Riems for providing HD11 (CCLV-RIE 1510) cells.

This work was supported by the European Union's Horizon 2020 research and innovation programme through the ZIKAlliance project (grant no. 734548). 


\section{About the Author}

Dr. Oliveira-Filho is a virologist at the Institute of Virology, Charité Universitätsmedizin Berlin. His research interests include the epidemiology and evolution of arthropod-borne viruses from animal reservoirs. Dr. Fischer is a virologist at the Institute of Virology, Charité Universitätsmedizin Berlin. His research interests include the epidemiology of arthropod-borne viruses in humans and animal reservoirs.

\section{References}

1. Petersen LR, Brault AC, Nasci RS. West Nile virus: review of the literature. JAMA. 2013;310:308-15. https:/ / doi.org/ 10.1001/jama.2013.8042

2. Rockstroh A, Moges B, Berneck BS, Sattler T, RevillaFernández S, Schmoll F, et al. Specific detection and differentiation of tick-borne encephalitis and West Nile virus induced IgG antibodies in humans and horses. Transbound Emerg Dis. 2019;66:1701-8. https://doi.org/10.1111/tbed.13205

3. Dodd RY, Foster GA, Stramer SL. Keeping blood transfusion safe from West Nile virus: American Red Cross experience, 2003 to 2012. Transfus Med Rev. 2015;29:153-61. https:/ / doi.org/10.1016/j.tmrv.2015.03.001

4. Ward MP, Scheurmann JA. The relationship between equine and human West Nile virus disease occurrence. Vet Microbiol. 2008;129:378-83. https://doi.org/10.1016/ j.vetmic.2007.11.022

5. Mattar S, Edwards E, Laguado J, González M, Alvarez J, Komar N. West Nile virus antibodies in Colombian horses. Emerg Infect Dis. 2005;11:1497-8. https:/ / doi.org/10.3201/ eid1109.050426

6. Morales MA, Barrandeguy M, Fabbri C, Garcia JB, Vissani A, Trono K, et al. West Nile virus isolation from equines in Argentina, 2006. Emerg Infect Dis. 2006;12: 1559-61. https:// doi.org/10.3201/eid1210.060852

7. Silva JR, Medeiros LC, Reis VP, Chavez JH, Munhoz TD, Borges GP, et al. Serologic survey of West Nile virus in horses from Central-West, Northeast and Southeast Brazil. Mem Inst Oswaldo Cruz. 2013;108:921-3. https://doi.org/ 10.1590/0074-0276130052

8. Ometto T, Durigon EL, de Araujo J, Aprelon R, de Aguiar DM, Cavalcante GT, et al. West Nile virus surveillance, Brazil, 2008-2010. Trans R Soc Trop Med Hyg. 2013;107:72330. https:/ / doi.org/10.1093/trstmh/trt081

9. Vieira MACS, Romano APM, Borba AS, Silva EVP, Chiang JO, Eulálio KD, et al. West Nile virus encephalitis: the first human case recorded in Brazil. Am J Trop Med Hyg. 2015;93:377-9. https:// doi.org/10.4269/ajtmh.15-0170

10. Martins LC, Silva EVPD, Casseb LMN, Silva SPD, Cruz ACR, Pantoja JAS, et al. First isolation of West Nile virus in Brazil. Mem Inst Oswaldo Cruz. 2019;114:e180332. https:/ / doi.org/ 10.1590/0074-02760180332

11. Fischer C, de Oliveira-Filho EF, Drexler JF. Viral emergence and immune interplay in flavivirus vaccines. Lancet Infect Dis. 2020;20:15-7. https:/ / doi.org/10.1016/S1473-3099(19)30697-8

12. Pauvolid-Corrêa A, Campos Z, Juliano R, Velez J, Nogueira RM, Komar N. Serological evidence of widespread circulation of West Nile virus and other flaviviruses in equines of the Pantanal, Brazil. PLoS Negl Trop Dis. 2014;8:e2706. https://doi.org/10.1371/journal.pntd.0002706

13. Moreira-Soto A, de Souza Sampaio G, Pedroso C, Postigo-Hidalgo I, Berneck BS, Ulbert S, et al. Rapid decline of Zika virus NS1 antigen-specific antibody responses, northeastern Brazil. Virus Genes. 2020;56:632-7. https://doi.org/10.1007/s11262-020-01772-2

14. Gibb R, Redding DW, Chin KQ, Donnelly CA, Blackburn TM, Newbold T, et al. Zoonotic host diversity increases in human-dominated ecosystems. Nature. 2020;584:398-402. https://doi.org/10.1038/s41586-020-2562-8

15. Swaddle JP, Calos SE. Increased avian diversity is associated with lower incidence of human West Nile infection: observation of the dilution effect. PLoS One. 2008;3:e2488. https://doi.org/10.1371/journal.pone.0002488

Address for correspondence: Dr. Jan Felix Drexler, Helmut-RuskaHaus, Institute of Virology, Campus Charité Mitte, Charitéplatz 1, 10117 Berlin, Germany; email: felix.drexler@charite.de 